\title{
El Desamparo del Lenguaje en Land to Light on de Dionne Brand
}

The Helplessness of Language in Land to Light on by Dionne Brand Azucena Galettini

Recebido em: 30 de julho de 2020 Aceito em: 15 de fevereiro de 2021
Es doctora y profesora en Letras (Universidad de Buenos Aires), traductora de inglés (IES en Lenguas Vivas "J. R. Fernández") y becaria post-doctoral de Conicet. Especialista en la poesía del Caribe anglófono, se desempeña como docente de literatura inglesa en profesorados y traductorados de inglés y dicta talleres de narrativa. Contato: agalettini@gmail.com Argentina 
PALABRAS CLAVE:

Poesía; Caribe anglófono;

Lenguaje; Dionne Brand.

KEYWORDS: Poetry;

Anglophone-Caribbean;

Language; Dionne Brand.
Resumen: Dionne Brand (Trinidad y Tobaso, 1953) es una de las poetas más reconocidas del Caribe anglófono y es una clara representante de la situación de la poesía en las Antillas de habla inglesa de los últimos treinta años. Esta literatura suele publicarse fuera de la región, pero, no por eso, deja de dar cuenta de las realidades caribeñas. En el presente ensayo trabajamos con el poemario Land to Light On (1997) para abordar la visión que se halla en él sobre el lenguaje, sus usos y posibilidades, frente al fracaso de los sueños revolucionarios del pasado y la realidad presente de discriminación y xenofobia. El lenguaje para Brand no puede volverse un refugio, un espacio habitable, un punto de anclaje, sino que resulta siempre un recordatorio del desamparo.

Abstract: Dionne Brand (Trinidad and Tobago, 1953) is one of the best-known poets from the Anglophone Caribbean and she is a clear representative of the situation of poetry in the resion during the last thirty years. This literature is published outside the region, but it still addresses Caribbean reality. In this essay, we work with the poetry collection Land to Light On (1997) to study the vision about language presented in it, its uses and possibilities, in the face of the failure of past revolutionary dreams and present realities of discrimination and xenophobia. For Brand, language cannot become a shelter, an inhabitable place, a point to anchor oneself, it is always a reminder of forsakenness. 
La poesía de los últimos treinta años del Caribe anglófono se caracteriza por la publicación por fuera de la región antillana y se observan tres grandes centros de inmigración para sus autores: Canadá, Estados Unidos y el Reino Unido. Si bien el cuestionamiento por la "caribeñidad" de una literatura que se produce fuera del propio Caribe era ya una preocupación para los escritores de la generación de 1950 (la primera en migrar y asentarse en los centros imperiales) ${ }^{1}$, desde la década de 1990 en adelante, ese cuestionamiento se volvió más acuciante debido a la preponderancia del marco poscolonial para el estudio de la región y el predominio de lo que se ha denominado el “modelo del Atlántico Negro”. Este surge a partir del reconocido libro de Paul Gilroy, El Atlántico Negro: Modernidad y doble consciencia (1993), en el que Atlántico Negro es entendido como una formación intercultural y transnacional que permitió pensar a las poblaciones y movimientos culturales de los afrodescendientes por fuera de las naciones en las que habían nacido o migrado, poniendo el eje en el pasado compartido, no sólo en tanto las experiencias de opresión, sino también en una raíz cultural común. Al poner el foco en la diáspora de los descendientes de esclavos, como característica común, se favoreció la formación de un nuevo canon en el que primaron las escrituras diaspóricas en detrimento de aquellos autores y obras que articulaban una visión localizada y local (Donnell, 2014, 126127), se privilegió lo cosmopolita por sobre lo local, al viajero por sobre el

1 George Lamming, a pesar de ser uno de esos escritores en el exilio, planteó en 1971 esa contradicción de manera muy gráfica, comparando la literatura con la cańa de azúcar, que se planta en el Caribe y se extrae para ser "refinada" en el exterior y luego reinsertada como producto final en las Antillas (Lamming, en Donnell y Welsh, 1996, 216). 
habitante, la movilidad por sobre la localización y el "otra parte" por sobre el aqui. Y si bien resulta innegable, como sostiene la crítica canadiense Sarah Phillips Phillips Casteel (2007), la importancia que han tenido "los estudios de la diáspora" para desarmar mitos de origen, también es cierto, como ella afirma, que este enfoque se ha extendido a todas las formas de locación. Se establece así una dicotomía entre el fijismo y la movilidad (Donnell 2006; 2014), pese a que, como ya sostenía Benítez Rojo $(1998,350)$ “... todo caribeńo sabe, al menos intuitivamente, que el Caribe es mucho más que un sistema de oposiciones binarias".

Por otra parte, en relación al marco poscolonial, dado que uno de los factores comunes más fuerte en las Antillas de habla inglesa es la experiencia del colonialismo (Donnell y Welsh, 1996), resultaría imposible pensar la literatura caribeña actual sin recurrir a los términos que plantea el pensamiento poscolonial. Asimismo, la crítica del poscolonialismo a la noción esencialista de la identidad, fundada en la persistente oposición contra un Otro que resulta eliminado y silenciado, está en plena sintonía con pensar "lo caribeńo" como constante apertura (Hall, 2010; Glissant, 2006; 1997; Bourriaud, 2009), en tanto la crítica poscolonial se plantea como "una particular filosofía del sujeto y por consiguiente propone un cierto tipo de reflexión sobre las identidades singulares y colectivas" (Mellino, 2008, 114). No obstante, esta corriente presenta una serie de peligros, entre ellos, el de la erosión de especificidades regionales al obliterar diferencias en aras de dar cuenta de las problemáticas afines (como puede ser la persistencia de las redes del colonialismo, la discriminación racial o el pasado de esclavitud 
como un referente constante). En relación con el Caribe, el poscolonialismo puede funcionar como un manto idealizador:

... el Caribe, con su realidad diaria de copresencia y mezcla, de formaciones sociales y culturales híbridas y sincréticas, resulta casi una utopía intelectual para el poscolonialialismo: un modelo ético en el que la diferencia es vista como múltiple, positiva y creativa. Este ideal es problemático pues es puramente intelectual y no vivido (Donnell y Welsh, 1996, 450, traducción propia).

En ese sentido, la imagen representada del Caribe no se condice con la realidad concreta que se experimenta en las Antillas. De esta manera, se considera a la región como un caso ejemplar del orden global (Mardorossian, 2005). Así, el Caribe pasó de una virtual invisibilidad desde una concepción de la modernidad occidental, a tener una posición privilegiada (Sheller, 2003). De hecho, Bourriaud (2009) define al Caribe actual como una maqueta original del mundo contemporáneo, por el cruce cultural artificial, puramente circunstancial pero que produce singularidades, presente en la región. En ese sentido, más allá de las diferencias lingüísticas y de los diferentes modelos de colonización, el trabajo de la poesía en el Caribe anglófono puede iluminar ciertos aspectos vitales para pensar, no sólo esa pequeña región dentro del "arco caribeño" (Glissant, 1997), que abarca desde el Nordeste brasileño, las Guyanas, la costa colombiana y el sur de México, sino también la poesía hispanoamericana en general, en un mundo que tiende hacia la mixtura, lo transnacional, el cosmopolitanismo $y$, en contrapartida, hace surgir nuevos movimientos hipernacionalistas, muchas veces xenófobos y racistas. De todas formas, es necesario recordar 
que ese "lugar privilegiado" que se le otorga al Caribe implica muchas veces una reapropiación exterior que, aun cuando sea para asignarle un valor positivo a la región, busca imponerle (a la región y a su literatura) una determinada concepción sobre lo que el Caribe es o debe ser, obviando especificidades y, en el caso de la literatura, analizando sólo aquello que se anticipa encontrar: lo diaspórico, la reflexión y crítica sobre el pasado colonial y la esclavitud. Por ello, en el presente trabajo nos detendremos en una autora que suele ser analizada precisamente desde ese marco para dar cuenta de otro aspecto poco iluminado en una de sus obras más reconocidas. Nos referimos a Dionne Brand, nacida en Trinidad y Tobago (1953) y emigrada a Toronto en 1970, donde habita desde entonces. Brand forma parte ya de lo que podría denominarse el "canon canadiense", como lo atestiguan los múltiples reconocimientos que ha recibido por su obra, ${ }^{2}$ el hecho de que publique en una de las casas editoriales más importantes (McClelland \& Stewart, perteneciente a Random House) o que haya sido nombrada poet laureate de Toronto entre 2009 y 2012. La obra en la que nos detendremos, Land to Light On (1997), ganó el prestigioso Governor's General Award al mejor libro de poesía de ese año y, en él, Brand explora las zonas rurales de Canadá, espacio que, según Phillips Casteel (2007),

2 Ha sido galardonada, entre otros con: el Governor General's Award para Poesía y el Trillium Book Award por Land to Light On (1997), el Pat Lowther Award por Thirsty (2002), el premio al Libro del Año de la Ciudad de Toronto, por la novela What We All Long For (2005), el Harbourfront Festival Prize en reconocimiento por su contribución a las letras, en 2006 - mismo año en que recibe una beca de la Academia de las Artes, Humanidades y las Ciencias de Canadá. En 2011 recibió el prestigiosísimo Griffin Poetry Prize por Ossuaries y en 2017 se volvió miembro de la Orden de Canadá. 
suele estar vedado a una inmigrante, pues la ciudad cosmopolita es el único espacio que se le permite habitar al sujeto diaspórico (al menos simbólicamente). En este poemario, observamos una deconstrucción del paisaje prototípico canadiense para dar cuenta de cómo esa supuesta “esencia canadiense" que puede anclajarse en el paisaje es mera fantasía. Se ha explorado ese eje en otro ensayo (Galettini, 2020), en el presente nos interesa centrarnos en un aspecto distinto que se observa en el poemario: su reflexión sobre el lenguaje y el acto de escribir poesía.

Land to Light On se compone de siete partes: la primera es "I Have Been Losing Roads", donde el sujeto lírico se halla en una zona rural de Canadá y, a partir del insulto recibido de parte de un hombre, blanco además, se abre una serie de reflexiones sobre por qué está en Canadá y no en la revolución soñada (que remite a la realizada por Maurice Bishop en Granada, de la que la propia Brand formó parte). La segunda se titula "All that Has Happened Since" y, en ella, se da cuenta de todo lo que ha pasado en la vida de la persona poética desde la fallida revolución. "Land to Light On" es la serie en la que se explora el porqué de la renuncia a pertenecer a un territorio, a una nación. La cuarta serie, "Dialectics", aborda el pasado en el Caribe y el vínculo con la familia luego de la partida. "Islands Vanish" evoca otra anécdota de maltrato: un policía que detiene el auto en el que va la persona poética con otros tres afrodescendientes, porque no entiende qué hacen ellos ahí, en el medio de la nieve, en una zona rural, no en el ambiente urbano cosmopolita donde son "aceptables". La sexta sección, "Through my Imperfect Mouth and Life and Way", es donde se reflexiona sobre el acto poético y 
"Every Chapter of the World" conecta con el poemario Inventory (2006), en tanto el sujeto lírico se detiene en un listado de muertes asociadas con la discriminación.

Cada una de estas partes se divide en poemas seriados, marcados con números romanos en mayúsculas, que, a su vez, se desglosan en otros "subpoemas", numerados en minúscula. No hay simetría entre las series, pues "I Have Been Losing Roads" contiene tres grandes poemas, mientras que las dos siguientes son un único gran poema subdividido en trece y seis, respectivamente. "Dialectis", en cambio, se divide en seis poemas mayores con pocas divisiones internas. "Islands Vanish" y "Every Chapter..." son un único poema, al igual que "Through my...", sólo que este se subdivide en tres.

Como hemos anticipado, en este libro Brand revela las construcciones literarias de la tradición canadiense y su vínculo con ellas, poniendo el acento en que se trata de construcciones. Además, ahonda en otra falsa ilusión, que va más allá de las idealizaciones espaciales, la de poder habitar el lenguaje como un lugar, buscar allí el anclaje que resulta imposible en el plano físico. Las reflexiones metapoéticas son importantes en la obra de Brand, pero aquí la preocupación por el lenguaje trasciende los cuestionamientos del carácter opresivo de las variantes oficiales del inglés, o el pasado de esclavitud (como se observaba, por ejemplo, en el poemario anterior a este, No Language Is Neutral). Si para todo poeta el lenguaje es un espacio de refugio, Brand desarma esa fantasía como si fuera una casa precaria barrida por el huracán. 


\title{
Deshabitar el Lenguaje
}

En su ya clásico ensayo "Migratorias", Julio Ramos retoma la frase de Adorno en "En el exilio la única casa es la escritura" para afirmar que:

La casa construida por la escritura pareciera así fundar un lugar compensatorio, armado precisamente a contrapelo de presiones externas [...]. La casa de la escritura es un signo trasplantado que constituye al sujeto en un espacio descentrado entre dos mundos, en un complejo juego de presencias y ausencias, en el ir y venir de sus misivas, de sus recuerdos, de sus ficciones del origen. (Ramos, 2009, 431-432)

Ante la pregunta sobre qué casa puede fundar la escritura, Ramos plantea que esta puede ser un lazo, "un encuentro con la tierra ausente" (436) o puede pensarse más en lo discursivo que en lo físico, donde lo que se pone de relieve son las "raíces portátiles" (mentalidad radicante, diría Bourriaud, 2009). ${ }^{3}$ Si bien esta última opción parece ser más acorde a la obra de Brand, en Land to... se manifiesta un rechazo a la fantasía del lenguaje como un espacio habitable que contenga y dé refugio. En primer lugar, porque la escritura quedará unida al fracaso de la revolución, así se observa en "I v":

\author{
Iv \\ All I could do was turn and go back to the house \\ and the door that I can't see out of. \\ My life was supposed to be wider, not so forlorn \\ and not standing out in this north country bled
}

3 Bourriaud toma la noción de "radicante" de la botánica: las plantas radicantes tienen raíces móviles y se trasladan creando raíces secundarias. Bourriaud no otorga mayor valor a la movilidad por encima de la localización, pero enfatiza que toda locación es transitoria. Una "mentalidad radicante" nos permite pensar una identidad dinámica que se define en el tránsito, en el movimiento. 


\author{
like maple. I did not want to write poems \\ about stacking cords of wood, as if the world \\ is that simple, that quiet is not simple or content \\ but finally cornered and killed. I still need the revolution \\ bright as the blaze of the wood stove in the window \\ when I shut the light and mount the stairs to bed. (7)
}

La referencia aquí es a su reacción luego del insulto recibido de parte de un hombre blanco que pasa en su camioneta. La sorpresa y desconexión que genera el improperio recibido ("cunt") es la que acompasa los diferentes subpoemas de esta serie "I". Se observa en este, como sostiene Fraser (2005), una ruptura con la construcción de cierto tópico de la literatura canadiense. El sujeto lírico establece que su intención no es la de cantar las loas a una vida rural, retirada y apacible, a un locus amoenus. La imagen que se evoca es una burla a la construcción de la vida en el norte canadiense, en la misma línea del "bled like maple", que hace referencia a la bandera y el arce como símbolo nacional. De hecho, esa es la otra cara del mito de la naturaleza silvestre canadiense: se la ve como el espacio de la autenticidad, de la sanación, del autoconocimiento, una vía de escape (Hammill, 2007). Brand rechaza esa posibilidad, pues es una simplificación ridícula para ella, pero lo que nos interesa es el vínculo con la revolución, pues lo que aparece como pensamiento frente al insulto es la discrepancia entre la vida soñada y la que se tiene. Así, se presenta el contraste entre el fuego de la revolución ("bright as the blaze") y la renuncia que implica que el sujeto lírico apague la luz y se vaya a dormir.

El enlace entre revolución y fuego ya había sido presentado en el poema anterior, "I iv": 


\author{
Yes, is here I reach \\ framed and frozen on a shivered \\ country road instead of where I thought \\ I'd be in the blood \\ red flame of a revolution. \\ I couldn't be farther away. \\ And none of these thoughts \\ disturb the starts or the pine \\ or the road or the red truck \\ screeching cunt along it. (6)
}

Es evidente la contraposición entre el frío canadiense y el calor de la revolución. Resulta llamativo el uso de "reach" en "here I reach", pues se genera una ambigüedad estructural interesante: puede tratarse tanto de una inversión, donde el orden canónico de la frase debería ser "I reach here”; o una denominada "cleft-sentence" donde la partícula $w h$ - ha sido eliminada: "here is where I reach". En el primer caso, "reach" funcionaría en su acepción de verbo de movimiento (un ejemplo sería "The boat reached the shore") y lo que se pondría de relieve es que se terminó “aquí” y no en la revolución. Esta opción es la que más se condice con el resto del poema, sin embargo, la otra posibilidad también está latente: "reach" como verbo intransitivo, que marcaría que el sujeto lírico se estira, tal vez en sintonía con el verso de "V i", "this wide country just stretches your life to a thinness" (43). Pero a su vez, si "reach" lleva en sí la idea de estirarse para tocar o alcanzar algo, connota también la opción de abrirse hacia afuera, un intento de conectar que ha sido brutalmente cercenado. En ese sentido, la contrapartida con la revolución estaría en "es aquí donde me ofrezco", en constraste con el 
ofrecerse en alma y vida a la lucha política. La aliteración de "framed and frozen" es la respuesta a ese estar "reached". El "framed" apunta al insulto recibido, que la pone en un marco a partir del "exact hatred / of the world" (4) del hombre que la insulta, tiñendo el "frozen" con el agravio: el adjetivo no referiría sólo al plano físico, al frío, sino también al estado de parálisis en que la situación la deja. No obstante, también late en "framed" el "to be framed", que se le haya tendido una trampa. Entonces, el estar "aquî" en lugar de la revolución es una trampa en la que ha caído. La sonoridad en "framed and frozen" conecta con "red flame", reforzando esa contraposición. Aunque el blanco nieve del paisaje no esté mencionado, se encuentra omnipresente, con lo cual visualmente se genera una oposición entre este y el "rojo sangre" de la revolución. Lo curioso es que en el siguiente poema, aunque se diga que se la necesita, pareciera que el sujeto lírico la abandona.

En la siguiente serie, "All that happened since", centrada, como ya se ha dicho, en qué ha pasado después de los sueños revolucionarios, se hace más evidente la asociación entre lenguaje y revolución. En el poema "IV x", se menciona a un hijo de Martí, que ha estado dando una conferencia, como uno de los últimos revolucionarios y se abre una reflexión sobre el lenguaje:

\section{$[\ldots]$}

we are waiting for some language to walk into

like a large house

with no rooms and no quarter

all waiting for his signal

we happen on what was wrong in the first place,

how the intangible took over, 
the things left in a language with careless or purpose [...]

the things kept secret with a hand pressed to the mouth

[...]

full knowing that we must throw our life away

and all impressions of ourselves

Comrades, perhaps this is what you might whisper

on the telephone to the young men who adore you still

"Goodbye, then. And well... betray your body". (36)

Esta imagen del lenguaje como una casa resulta central. Cabe destacar que Gastón Bachelard $(2000,27)$ sostenía que la casa es nuestro rincón del mundo, nuestro primer universo, pues es un cosmos en sí misma. Todo espacio habitado lleva como esencia la noción de casa, pues esta “[...] alberga el ensueño, la casa protege al soñador, nos permite soñar en paz” (Bachelard, 2000, 29) y, en la relación con esta, “[...] se revela una adhesión, en cierto modo innata, a la función primera de habitar" (27). El deseo de entrar al lenguaje como a una gran casa está asociado con ese impulso: habitar el lenguaje como nuestro rincón en el mundo, encontrar en él protección y también solaz para sońar. Aquí el idioma que se quiere encontrar es el de la revolución, ése que permitía avizorar un mundo distinto. El verso "we happen on what was wrong in the first place" juega con las temporalidades mediante el uso del creole. "Happen" remite, entonces, al presente y al pasado al mismo tiempo. Gramaticalmente, dado 
el verbo "was" en la proposición sustantiva que se abre con "what", que depende de "happen" como verbo principal, se estima que "happen" es la pronunciación de "happened", pues la elisión del sufijo del pasado simple es propia del creole. Se remite así a un tiempo anterior al de la salida de la conferencia, al pasado de su juventud revolucionaria. Sin embargo, la tensión temporal está allí, y el "happen" funciona como elemento bisagra entre el presente de "we are waiting" y el pasado de "was" y "took over". Observamos, pues, el deseo de encontrar un lenguaje que ampare en la instancia enunciativa que nos ubica fuera de la conferencia, pero, en el pasado revolucionario, ya se ha revelado que esa búsqueda de refugio es una idealización, el lenguaje de la revolución estaba cargado de "things kept in secret with a hand pressed to the mouth": todo aquello que es intangible y que en el poema estará asociado con lo no dicho o silenciado. ${ }^{4}$ La idea de renunciar a la propia vida ("throw life away") y traicionar al cuerpo ("betray your body") habla de los sacrificios no dichos que exige la revolución: traicionar el cuerpo implica, además, no oír el instinto de supervivencia. Lo no dicho, entonces, se asocia a lo que esos "camaradas" dan por sentado y no hacen nunca explícito, el precio que se paga en

4 La noción de "casa" en Brand es compleja. En el poema "V ii" se dice "your house behind your eyebrows" (44) como si esta sólo pudiera ser una construcción mental y nunca un espacio físico concreto. En "I i" (3), desde la casa en la que se está resulta imposible invocar el patio que se asocia con la infancia del Caribe, contradiciendo la visión de Bachelard de que una casa permite la evocación de todas las otras que se han habitado (si tomamos, claro está, el patio como parte de la casa). En el "I've losing roads", la casa no es realmente un refugio, aunque el sujeto lírico se esconda en ella y cierre todas las puertas, la siente endeble, como lo demuestra el siguiente verso de "II iv": "this/ house is only as safe as flesh" (11). La casa se vuelve más bien una prisión en la que encerrarse frente a la amenaza externa. 
las revoluciones. Cabe destacar que el desencanto de Brand está teñido, además, por la traición interna que se experimentó en la revolución en Granada, hecho que se hace palpable en su libro Chronicles of a Hostile Sun. Aquí, como en buena parte de su obra, el desencanto reaparece, pero toma otros visos más abarcadores, pues se detiene en ese lenguaje de la revolución que, sin embargo, se presenta como hipócrita.

Dos poemas más adelante, luego de que en "IV xi" se vuelva sobre el recuerdo de la invasión estadounidense en Granada, ${ }^{5}$ se retoma una reflexión metapoética sobre la propia voz, que tan fácilmente puede ser denominada "amargada". 6

\section{IV xiii}

why this voice rank and ready to be called bitter again, liquor doesn't soothe it and books either, self saboteur, it could be nice and grateful but Fanon had it, native envy, watery and long as that bloody sea, envy for everything then, kitchen knives their dullness or sharpness, shoes their certainty, envelopes their letters, clocks their lag, paper its clarity, envy to the participle and adverb, the way they own being, ripe envy full as days [...] (38)

5 Este poema puede leerse en perfecta resonancia con "I Used to Love the Dallas Cowboys" de Sans Souci and Other Stories (1989), donde la protagonista, que está en Granada durante la invasión de la denominada misión "Urgent Fury”, recuerda su vida en Canadá mientras está tirada en el suelo de la casa, oyendo pasar los aviones estadounidenses y temiendo que caiga un misil sobre la vivienda.

6 Esto es una mención velada a ciertas críticas que Brand suele recibir sobre lo agresivo de su tono. Su estilo de versos largos, de ritmo asfixiante, que otorga un sentido de urgencia a su poesía, es visto como una muestra de un sujeto lírico en un permanente estado de irritación. 
La intertextualidad con Los condenados de la tierra de Frantz Fanon, en tanto el deseo de posesión de aquello que los blancos tienen, aquí está cruzada por la necesidad de poseer el lenguaje como ellos lo hacen: junto con objetos como cuchillos, zapatos, surge "their certainty", que si bien pareciera estar modificando a "shoes" (como si la frase entera, cortada por la elisión fuera "of their shoes we envy their certainty"), es más general y abarca a los blancos, pues está conectado con "the way the own being". "Envelopes", "letters", "paper”, todos remiten a la idea de la palabra escrita y por ende el lenguaje. Resulta particularmente sugestiva la frase "envy to the participle and/ the adverb”, pues no se envidia el verbo, sino aquello que podría considerarse "accesorio", lo que es más sutil, poder darse el lujo de valerse de los adverbios y participios. Leemos "clarity" y "sharpness" [en tanto nitidez o perspicacia/ agudeza] en la misma línea de "certainty": la capacidad de valerse del lenguaje con absoluta confianza en que se lo posee, que es una propiedad más como los zapatos o los cuchillos, como la mesa o la cama del colonizador de la que hablaba Fanon. Así, ese deseo de habitar el lenguaje como una casa, estaría ligado a esa posesión, a sentirse dueños de él. Se vuelve imposible por lo oculto, lo dejado a propósito o al descuido en él, asociado a la problemática étnica, a que no se posee realmente el lenguaje sino que se es poseído por él.

Fraser (2005) sostiene que, en este poemario, el lenguaje funciona como una "tierra" metafórica desde la que la persona poética puede "iluminar" y asocia ese hecho con la construcción de "land", propia de la literatura canadiense que Brand parece estar poniendo en entredicho. El lenguaje, entonces, "aprisiona tanto como libera" al sujeto lírico (Fraser, 2005), debido 
al final del libro en el que la persona poética se presenta a sí misma como una presa que no hace más que dar vueltas y vueltas en su celda. ${ }^{7}$

Si bien es posible afirmar, como lo hace Fraser (2005), que Brand establece un paralelismo entre "land" y "language" (y la aliteración no es casualidad), a su vez, el deseo de habitar un lenguaje como un lugar en Brand es muy problemático. De hecho, en este poemario, el lenguaje es conflictivo en varias situaciones. En primer lugar, ante el "cunt" que le grita el hombre de la camioneta, el sujeto lírico no logra reapropiarse del lenguaje, que ha sido utilizado como arma en su contra. No se logra emitir sonido, las palabras se caen, ineficientes:

\section{I iii}

I lift my head in the cold and I get confuse. It quiet here when is night, and is only me and the quiet. I try to say a word but it fall. Fall like the stony air. I stand up there but nothing happen. Just a bank of air like a wall. I could swear my face was touching stone. I stand up but nothing happen, nothing happen or I shouldn't say nothing. I was embarrassed. standing like a fool, the pine burdened in snow, the air fresh, fresh and foreign and the sky so black and wide I did not know which way to turn except to try again, to find some word that could be heard by the something waiting. My mouth could not find a language I find myself instead, useless as that. I sorry. I stop by the mailbox and I give up. (5)

7 "She may not leave here anything but a prisoner / circling a cell, // cutting the square smaller and smaller and walking into herselfl finally, brushing against herself as against surprising //flesh in a dark room [...] (103) 
Lo interesante es ver cómo las palabras no funcionan: se intenta lograr decir algo ante el paisaje como espectador, pero no hay lenguaje posible para hacerlo. El "cunt" que le fue gritado genera un quiebre en el lenguaje que desconecta a la persona poética. Resulta curioso que lo que se encuentra sea a sí misma. Si en el cierre de No Language Is Neutral ese encuentro era gozoso, ${ }^{8}$ aquí sólo confirma la inutilidad. Es llamativo el "nothing happen" reiterado, pues aunque indique el grado de parálisis en el que ha quedado la persona poética, también señala que sólo la han insultado. Sin embargo, la repetición implica su misma cancelación. Esa "nada" significa todo para ella, pues la deja muda, inútil. El final del poema aporta cierta visualidad a lo que ha ocurrido, pues nos ubica en la escena: la persona poética camino al buzón, un hombre pasa en una camioneta y la insulta.

La relación entre lenguaje y paisaje que se construye es de una profunda tensión. El aire tiene la pesadez de una piedra y las palabras caen frente a él: funciona como un muro que el sujeto lírico siente contra su cara. La

8 Los versos finales en No Language Is Neutral son los siguientes:

I saw my own body, that

is, my eyes followed me to myself, touched myself

as a place, another life, terra. They say this place

does not exist, then, my tongue is mythic. I was here

before (50).

Vemos aquí que la mirada se vuelve sobre sí misma, en un desdoblamiento que sonoramente conlleva una ambigüedad (mis ojos/mis yo) y que implica también que esta se corporaliza, por eso puede tocarla. El cierre del poemario implica un reencuentro, es decir ese "lugar inexistente" que no es más que encontrarse a sí misma como un lugar al cual pertenecer, ya fue visitado por el sujeto lírico. Esto implica un retorno a cierto espacio primigenio, ancestral, una reunión consigo misma que parecía imposible pero que el encuentro con la amada (pues ese último poema es amoroso) permite. 
aparente belleza de la descripción del pino cargado de nieve (en el adjetivo "burned" también late la idea de estar agobiado por el peso), del aire "fresh", adjetivo que se repite dos veces - como si, con ello, se lograra cancelar el valor opresivo que se le dio antes a compararlo con piedra y muro -, se desarma con la aliteración en "foreign", pues se restablece la distancia abierta entre el sujeto lírico y el paisaje. Así, en este poema, vemos cómo el lenguaje puede ser vehículo de daño (el insulto) y, al mismo tiempo, cómo la incapacidad de apropiarse de él deja al sujeto lírico indefenso, incapaz de reaccionar.

Otra instancia en la que vemos la relación problemática con la palabra es cuando se pone de manifiesto que el "lenguaje de la revolución” se ha convertido en una serie de estereotipos que circula en los congresos sobre "porno-multiplicidad, el mundo cotidiano, el mono significante, el momento poscolonial, la milicia de Michigan, el ciberespacio" (32). Sobrevivir a la muerte de las creencias políticas ("The body bleeds only water and fear when you survive/ the deaths of your politics") es otra forma de mudez, que no equivale a quedarse sin palabras, sino todo lo contrario: se está "full of smartness" (15), llenando auditorios, sacando diccionarios y revistas con referato. Esa segunda "muerte de su política" la obliga a renunciar a ese tipo de funcionamientos ("Then I lost, well, I gave up the wherewithal" [15]). ' Se observa así la postura de Brand con respecto a los ejes desde los cuales suele estudiarse su literatura: la ridiculización esconde también la

9 El poema de donde provienen estas citas, "III iii" (15), es el que da título a la sección ("Loosing Roads". Lo interesante del olvido y pérdida que la persona poética establece es que Granada permanece indeleble, pese a que el sujeto lírico quisiera olvidarla. 
autocrítica, pues si se señala la inutilidad de toda esa "palabrería" que no parece cargada de ningún contenido político, ni de ninguna posibilidad de operar sobre el mundo real y sus tragedias, también ella es parte de ese juego que terminará por abandonar.

En tercer lugar, en la sección "Dialectis", dedicada a la familia, Brand establece que surge en ella un "nuevo lenguaje" ("IX i", 63) que nada tiene de liberador porque no logra decirle algo a sus parientes que no sea "awkward and insulting" (63). Esto ocurre debido a la actitud del sujeto lírico:

\section{$[\ldots]$ as if I could not trust you to understand my new language which after all I had made against you, against the shapes of your bodies, against your directions, your tongues, the places your feet took you [...] (63)}

Sin embargo, la persona poética sabe que su partida implica también un distanciamiento consigo misma: "Out of them. To where? As if I wasn't them" (69). La distancia que se abre entre ella y su familia no puede ser traspasada por el lenguaje, pues este ya no sirve para comunicarse con ellos. La equiparación del sujeto lírico con sus parientes en "as if I wasn't them" establece que su "nuevo lenguaje" implica también un quiebre interno, la posibilidad de conectar con una parte de sí. ${ }^{10}$

Ante esas posturas conflictivas respecto al lenguaje, habitarlo implica romper con la fantasía de que puede encontrarse una casa, ese espacio íntimo

10 Aunque no se lo dice abiertamente, ese nuevo lenguaje también podría estar asociado con los ideales revolucionarios. Desde esta perspectiva, es posible asociar a la persona poética de la sección "Dialects" con la Verlia de In Another Place, Not Here, que, al unirse al "movimiento", pasa a despreciar la poca conciencia racial de su familia y se vuelve incapaz de comunicarse con ellos. 
dentro de él. No se trata sólo de que debe desconfiarse del lenguaje puesto que este construye un espacio idealizado irreal, una "tierra" a la que pertenece, como lo lee Fraser (2005), al plantear que a eso renuncia Brand, sino que el lenguaje en sí mismo no es suficiente en tanto es una fuerza que impulsa a anclarse, a buscar refugio.

Brand muestra aquí que el lenguaje se vuelve una suerte de paisaje, con el anhelo de una pertenencia tranquilizadora. Escribir desde el género y la raza, como se planteaba en No Language Is Neutral, ${ }^{11}$ ya no parece ser suficiente, no hay nada reparador en ello, sino más bien una necesaria compulsión. Y será solo en relación con un otro que el tono de Brand pierda dureza. Así, la apertura de "Through my Imperfect..." para ser una confesión amorosa que es, a su vez, la admisión de una compulsión:
I know you don't like poems, especially mine and especially since mine never get told when you need them, and I know that I live some inner life that thinks it's living outside but isn't and only wakes up when something knocks too hard and when something is gone as if gazing up the road I miss the bus and wave a poem at its shadow. But bus and shadow exist all the same and I'll send you more poems even if they arrive

11 En ese poemario se afirma:

Each sentence realised or dreamed jumps like a pulse with history and takes a side. What I say in any language is told in faultless knowledge of skin, in drunkenness and weeping, told as a woman without matches and tinder (31) Se observa así que Brand plantea desde dónde nace su escritura, desde una visión ideológica anclada en la raza y el género. 


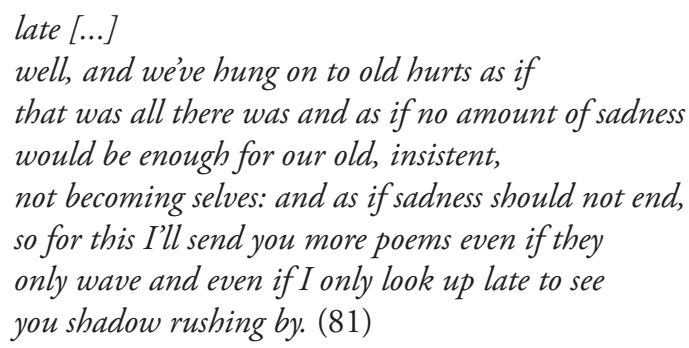

En "On Poetry", Brand reflexiona sobre la inutilidad aparente de la poesía: "Often there's been no reason whatsoever to write poetry. There are days when I cannot think of a single reason to write this life down" (1998, 196). Su militancia política y social - organizar una protesta, ayudar a una indocumentada a parir en Toronto sin que la deporten - se encuentra en lucha contra el acto de escritura. Y pese a que no niega que frente a esas realidades sigue considerando que la poesía es inútil, esta también cumple un fin: "[...] if I can give myself a moment, I would say it's been a relief to write poetry, it's been just room to live” (Brand, 1998, 195). Es interesante que no dice "a room to live". La poesía construye un espacio habitable, donde respirar es posible, pero no es en sí un espacio para habitar. Eso implicaría comodidad, seguridad, y el lenguaje poético implica lucha y riesgo: "Poetry is here, just here. Something wrestling with how we live, something dangerous, something honest" (Brand, 1998, 196).

Cabe destacar la presencia del deíctico, claramente no como una marca de espacialidad, sino como indicador de que la poesía es algo que la habita, está en ella en constante pelea con la vida ordinaria, abriendo caminos. Tal vez pueda pensarse en los términos de Francine Masiello $(2013,96)$, 
quien plantea que la poesía es un espacio de resistencia, pues "denuncia el espectáculo del comercio global" y "propone un tipo de experiencia otra respecto del lenguaje, que ha sido suprimida por el tráfico de la literatura light” (96). Tal vez se trate sólo de la conciencia del rol que la poesía cumple en su vida. De todas formas, el envío de poemas inútiles en la cita de Land... debe entenderse en esos términos: la poesía puede no servir de nada, pero aun así es imposible renunciar a ella, está siempre aquí. El lenguaje poético la habita, pero eso no quiere decir habitarlo, verlo como un lugar al cual anclarse.

En ese sentido, Brand permanece crítica a sus propias tendencias. La serie "Every Chapter of the World.", en la que se da un cambio de primera a tercera persona, como si el sujeto lírico se desdoblara y se mirase desde la distancia, se vuelve sobre las muertes que ocurren en el mundo debido a la discriminación y desigualdad y se dice: "No she cannot speak of this or that massacre, this/ or that war like a poet. Someone else will do that. She // sees who dies [...]" (98). Y se dedica a ese listado de muertos que observa. Sin embargo, luego es capaz de afirmar: "[...] inventory is useless now but just to say, / no so fast, not so clever, boy, circumnavigating// parentheses may be easy but not the world" (101).

La escritura de estos hechos puede situar al que escribe en esa actitud de navegar entre paréntesis, bajo la creencia de que el control sobre un texto equivale a controlar lo que ocurre en el mundo, esa distancia ya denunciada en "Through my Imperfect..." entre la vida interior y el mundo externo, esa vida que no es vida. Por eso se le demanda "[...] surrender all parentheses/ all 
arguments, this world in that one, that one in this // all tangled [...]" (102). Si como signo el paréntesis une y separa los componentes de una frase, un adentro y afuera, se llama a la persona poética a abandonar las divisiones, el adentro y afuera de la "vida interna" y la "vida real". Los paréntesis están asociados, entonces, con las declaraciones de buena fe:

\section{[...] but surrender the parentheses, what are those but tongues slipping in and out of a mouth, pages}

sounding like wings beating in air, what but the sound of someone washing their hands quickly, beating their lips red. (102)

La utilidad de esos paréntesis es inexistente, la comparación con el ruido de un aleteo les quita cualquier trascendencia, cualquier capacidad de operar en el mundo y, por ende, sólo sirven para dejar la conciencia tranquila ("washing their hands") y que nada cambie en el plano material. Esto no implica una liberación, pues se sucumbe al ron y las últimas imágenes remiten a una presa dando vueltas y vueltas en (circunnavegando, tal vez) una celda. Fraser (2005) ve allí la conciencia de que el lenguaje es una prisión y que "ninguna resistencia en el lenguaje es posible sin sacrificio". Sin embargo, aquí afirmamos que la desesperación con la que Brand cierra el poemario está asociada con la idea de renunciar a la poesía. Realizar el inventario poético de las muertes es inútil y, sin embargo, no dar cuenta de ellas implica renunciar, como quien se entrega a la beneficencia ("surrender then if it means powdered milk if it means / rice, semolina, surrender for airflights out of barren// ice, barren water, barren villages” [102]). 
Abandonar los paréntesis también podría ser olvidar las salvedades, las diferencias: los comentarios entre paréntesis como ese espacio donde se cuestiona, corrige, morigera, lo presentado. Renunciar a ellos sería entonces aceptar verdades absolutas, convirtiéndose en "[...] the tired voting in surrender". La locura surgiría por abandonar la creencia en la poesía como algo "peligroso y honesto" (Brand, 1998, 196), condenándola al mero devaneo.

Claramente, Brand no considera que el inventario sea inútil, pues, en Inventory, se construye su trabajo poético precisamente a partir de las listas. Desde esta perspectiva, ese poemario funcionaría como continuación de Land... donde se opta por una postura que desarma las imposibilidades de este: adoptar una persona poética que necesita repetir incesantemente la lista de muertes. Pero si en ese libro al menos se reconoce la existencia de la felicidad, aunque sea para afirmar que no le compete como poeta ocuparse de ella, en Land... la imagen de cierre es aún más agobiante. En No Language is Neutral... el encuentro consigo misma era liberador, aquí el roce con su yo la toma por sorpresa (walking into herself/ finally, brushing against herself as against surprising //flesh in a dark room [...], 103), como si toparse consigo misma fuera algo que no pudiera concebir, como si la persona poética se viera, sintiera, como una otra. Tal vez porque el "nuevo" lenguaje de la distancia la ha dislocado de una parte de sí, tal vez porque el brutal inventario de muertes hace que le resulte impensable un reencuentro de sí misma. 


\section{Abandonar el refugio}

En Land to Light On Dionne Brand presenta una visión del lenguaje que deja al sujeto lírico desamparado, pues este no permite un verdadero anclaje, no puede ser habitado como un lugar, no permite un verdadero encuentro con otros, ni siquiera consigo mismo, es vehículo de daño y ni siquiera puede blandirse como un arma para defenderse. Si la revolución podía ser una instancia que invitaba a crear un nuevo lenguaje, vemos en este poemario el desencanto con esa fantasía: no se lo puede poseer, no se tiene, desde la conciencia étnica, la misma libertad que los blancos, esa sensación de tener derecho, de ser dueños del lenguaje, como de un par de zapatos. El lenguaje de la revolución implica también una traición, no sólo al propio cuerpo ("betray your body", se decía), sino que lo que se da, por supuesto, lo que no se dice (el sacrificio que conlleva) es parte también de ese lenguaje y se lo presenta como un secreto que nunca se le susurra a los más jóvenes. El "mundo nuevo" que ese lenguaje revolucionario debería crear (que la revolución política debía crear) termina licuado, carente de sentido, en congresos, charlas, en la apropiación academicista sin impacto en el mundo real. Frente a eso, solo resta el inventario de muertes. En ese sentido, es interesante pensar el planteo de Brand más allá del Caribe anglófono o del público canadiense. ¿Cómo escribir cuando los sueños revolucionarios (y los de Granada fueron los de buena parte de América Latina en la década de 1970) ya no existen, cuando su lenguaje se ha degradado, cuando ya se ha visto aquello que ocultaban? ¿Cómo escribir sin ser mera poesía de denuncia, frente a la ferocidad del neoliberalismo, el supuesto cosmopolitismo que sigue 
escondiendo xenofobia y racismo? Brand se plantea, frente al desamparo del lenguaje, si vale la pena seguir escribiendo, como Adorno alguna vez afirmó que no se podía escribir poesía después de Auschwitz. Su respuesta es que, para ella, no existe otra opción posible: la poesía es una compulsión necesaria, incluso si a veces la presente como opuesta a la vida en sí, como un pasaje al mundo interior que la desconecta del exterior. Pero, para entregarse al acto de escribir, hay que renunciar a la fantasía de que el lenguaje puede ser un bálsamo, un lugar habitable y seguro; hay que abrirse a la lucha que trae consigo frente a la propia vida, aceptar el riesgo que conlleva; dejar, al fin de cuentas, que ese ideal de refugio sea barrido por el huracán.

\section{ReFERENCIAS BIBLIOGRÁfICAS}

Bachelard, Gaston. La poética del espacio. Buenos Aires: FCE, 2000.

Benítez Rojo, Antonio. La isla que se repite. Edición definitiva, Barcelona: Editorial Casiopea, 1998.

Bourriaud, Nicolas. Radicante. Buenos Aires: Adriana Hidalgo editora, 2009.

Brand, Dionne. Land to Light On. Ontario: McClelland \& Stewart, 1997.

Brand, Dionne. Bread out of Stone. Recollections on Sex, Recognitions, Race, Dreaming and Politics. Toronto: Vintage Canada, 1998.

Donnell, Alison; Welsh, Sarah Lawson (comps). The Routledge Reader in Caribbean Literature. Londres \& Nueva York: Routledge, 1996.

Donnell, Alison. Twentieth-Century Caribbean Literature. Critical moments in anglophone literary history. Londres: Routledge, 2006. 
Donnell, Alison. "The Questioning Generation. Rights, representations and Cultural Fractions in the 1980s and 1990s". In: Buknor, Michael y Donnell, Alison (eds.) The Routledge Companion to Anglophone Caribbean Literature. Nueva York, Londres: Routledge, 2014, 124-133.

Donnell, Alison; Welsh, Sarah Lawson (comps). The Routledge Reader in Caribbean Literature. Londres \& Nueva York: Routledge, 1996.

Fraser, Kaya. "Language to Light On: Dionne Brand and the Rebellious Word." Studies in Canadian Literature / Études en littérature canadienne [Online], 30.1 (2005): s/n. Web. Recuperado de <https://journals.lib.unb.ca/index.php/scl/ article/view/15283/16374>. Consultado en julio de 2020.

Galettini, Azucena. “(Des)componer una tierra: Canadá repensada desde la escritura topográfica en Land to Light On de Dionne Brand". Interfaces Brasil/Canadá, Revista Brasileira de Estudos Canadenses. [Online], 20 (2020): 1-22, Acceso 8 de enero 2021.

Gilroy, Paul. The Black Atlantic: Modernity and Double Consciousness. Londres, Nueva York: Verso, 1993.

Glissant, Édouard. Le discours antillais. París: Éditions Gallimard, 1997.

Glissant, Édouard. Tratado de todo-mundo. Barcelona: El Cobre Ediciones, 2006.

Hall, Stuart. "Cuándo fue lo poscolonial. Pensando en el límite". In: Eduardo Restrepo, Catherine Walsh y Víctor Vich (Eds.) Sin garantías: trayectorias y problemáticas en estudios culturales. Popayán, Colombia: Envión Editores, 2010, 563-582.

Hammill, Faye. Canadian Literature, Edimburgo: Edinburgh University Press, 2007.

Lamming, George, Sander, Reinhard y Munro, lan. "The Making of a Writer: a Conversation with George Lamming”. In: Donnell, Alison y Welsh, Sarah Lawson (comps). The Routledge Reader in Caribbean Literature. Londres \& Nueva York: Routledge, 1996. 
Mardorossian, Carine. Reclaiming Difference, Caribbean Women Rewrite Postcolonialism. Charlottesville: University of Virginia Press, 2005.

Masiello, Francine. El cuerpo de la voz (poesía ética y cultura). Rosario: Beatriz Viterbo Editora, 2013.

Mellino, Miguel. La crítica poscolonial. Descolonización, capitalismo y cosmopolitismo en los estudios poscoloniales. Buenos Aires: Paidós, 2008.

Phillips Casteel, Sarah "Introduction. Landscaping in the Diaspora". Second Arrivals: Landscape and Belonging in Contemporary Writing of the Americas. Carlottesville: University of Virgina Press, 2007.

Ramos, Julio. "Migratorias". Desencuentros de la modernidad en América Latina. Caracas: El perro y la rana, 2009, 431-444.

Sheller, Mimi. Consuming the Caribbean: From Arawaks to Zombies. Londres: Routledge, 2003. 
